\title{
Preface: Wetland services and management
}

\author{
Chris Joyce
}

Published online: 26 May 2012

(C) Springer Science+Business Media B.V. 2012

Wetlands function as long-term stores for nutrients and carbon, as filters for pollution and sediment, as buffers against coastal storms and flood events, and as habitats for biological diversity, including many rare species (Mitsch \& Gosselink, 2007). These functions provide vital services that benefit society, including food, peat, building material, amenity, flood mitigation, aquifer recharge and climate regulation (Turner et al., 2007). The plethora of wetland services is partly due to the diversity of wetland types, as they include natural wetlands such as peatlands (bogs and fens), swamps, and marshes, semi-natural wetlands that are maintained by regular management, such as wet grasslands, and created wetlands, including pond systems constructed to treat wastewater. Nevertheless, all wetlands are unified by their defining character: a water table sufficiently high (at least periodically) to influence substrate properties and vegetation, and therefore biodiversity. Managing the wetland resource effectively and sustainably is increasingly challenging and important because wetlands are still being lost through drainage, infilling or inappropriate management, yet it is becoming ever more evident that the

Guest editor: Chris B. Joyce / Wetland services and management

C. Joyce $(\bowtie)$

School of Environment and Technology, University

of Brighton, Brighton, UK

e-mail: C.B.Joyce@brighton.ac.uk services they provide are vital for society (Millennium Ecosystem Assessment, 2005).

The collection of papers in this special issue indicates how knowledge of wetland services is being extended by European members of the Society of Wetland Scientists (SWS), including new benefits to society, novel approaches, and management considerations. The SWS is an international organisation with more than 2,500 members that promotes scientific understanding, management and sustainable use of wetlands. The 5th Annual Meeting of the European Chapter of the SWS was held from 26th to 28th May 2010 in Tramore, Ireland, to consider the benefits that wetlands give to society and how wetlands can be managed so that those benefits can be delivered sustainably. There were 35 oral presentations and 15 poster presentations, representing 16 countries, as well as inspirational field visits to wetlands created in stream catchments at Dunhill and Annestown. These provide a range of ecosystem services appreciated by the local community, including fisheries, nutrient removal, landscape enhancement and biodiversity benefits. The following 12 papers are drawn from the Tramore meeting and are introduced briefly below. The papers are sequenced such that the initial ones particularly illustrate the benefits provided by wetlands and ecosystem functioning (with a belowground emphasis), followed by studies examining aspects of restoration and creation that aim to enhance wetland service provision.

Relatively few studies of wetland services have yet to place sufficient emphasis on their socioeconomic 
importance, but Morrison et al. (2012) highlight the vital role that papyrus (Cyperus papyrus L.) swamps play in sustaining riparian livelihoods around Lake Victoria, Kenya. The services provided by papyrus wetlands include commodities traded or sold at local markets, which are appreciated to the extent that one local community has successfully restored a papyrus wetland. Biodiversity is a vital service provided by wetlands; Hannigan \& Kelly-Quinn (2012) investigate the role of habitat variables in explaining macroinvertebrate diversity in open water habitats in Irish peatlands. They note the importance of hydrological regime and Sphagnum presence in controlling invertebrate communities in peatland pools, and present a good example of how life history traits can be used to elucidate patterns in ecological data beyond the traditional species approach (Menezes et al., 2010). Turlough wetlands in Ireland provide agricultural services through their grazing potential, but Kimberley et al. (2012) demonstrate that extended flood events in these ephemeral karst wetlands are likely to reduce their grazing value due to modifications in their soil properties that encourage sedge-dominated vegetation. The study therefore serves not only to introduce these unusual wetlands but to illustrate how multiple services provided by wetlands, such as grazing, flood storage, and biodiversity, may be compromised. The consequences of wetland use are considered by Salm et al. (2012), who estimated the effects of drainage and peat extraction on greenhouse gas emissions from Estonian peatlands. Meanwhile, Dušek et al. (2012) apply a novel approach for wetland ecosystems to investigate carbon cycling in a sedgegrass marsh in the Czech Republic, highlighting how a variable water regime markedly affects carbon accumulation. Both studies highlight the fundamental importance of hydrological conditions in controlling wetland functioning, and the critical role that wetlands have in terms of carbon cycling, and therefore their potential for ameliorating the possible consequences of climate change. Eutrophication, however, remains one of the biggest environmental problems facing wetlands, but knowledge of its effects on soil functioning in wetlands lags behind that of aboveground ecological impacts (Bardgett \& Wardle, 2010). Kaštovská et al. (2012) address these issues by experimentally fertilising two wet grasslands on contrasting mineral and peaty soils, and quantifying carbon and nitrogen transformations. They found that fertilization affected carbon transformations more than nitrogen, although it also seemed to accelerate soil nitrogen cycling and losses in the organic soil.

The remaining papers emphasise human interactions with wetlands and their services, in terms of management, restoration or creation. Abandonment of formerly managed sites is a widespread and persistent threat in many semi-natural wetlands that depend upon regular vegetation management, such as cutting or grazing, to maintain their characteristic biodiversity and other ecosystem services (Rosenthal, 2010; Schrautzer et al., 2011). Berg et al. (2012) show that restoring abandoned wet grasslands in Estonia by reinstating cutting management may be a slow process, and that plant communities are possibly more responsive to hydrological regime. Steffenhagen et al. (2012) demonstrate the important role of aquatic macrophytes for nutrient cycling in degraded, rewetted fens in Germany, suggesting that such vegetation can be used to accelerate the restoration of wetlands by facilitating low nutrient status. The concept of Integrated Constructed Wetlands (ICW) has attracted attention in recent years (Scholz et al., 2007) as it describes wetland systems that potentially provide multiple service benefits, including water cleansing, biodiversity enhancement, carbon storage and amenity. Two studies seek to develop the concept in this special issue. Harrington et al. (2012) report a mesocosm trial of ICWs that proved effective for the removal of nutrients in swine waste, suggesting that ICWs may be a viable tool for more sustainable management of agricultural catchments. Further, the review by Beccerra-Jurado et al. (2012) concludes that some relatively minor design improvements to the ICW system would maximise their potential to enhance macroinvertebrate diversity in such catchments, and reinforces the importance of stakeholders engaging in management so that the wetlands can provide the services required by the local community. While examples of wetland potential or success in providing ecosystem services are welcome, it is just as important that scientists and practitioners are aware of limitations in wetland performance. Vymazal \& Šveha (2012) found that two constructed wetlands treated with municipal sewage in the Czech Republic were ineffective in retaining alkali metals. However, Koiv et al. (2012) present a potentially innovative use of the filter materials from constructed wetlands that are rich in phosphorous following wastewater treatment, 
which their experiment suggested are a promising means of improving or amending forest soils.

The collection of papers in this special issue indicates how members of the European Chapter of the SWS are at the forefront of research into managing the wetland resource for the services it provides. The diversity of wetland types and their biogeographical characteristics means that it is often easiest to address wetland issues with a narrow focus, in isolation, or on a site-specific basis. This, however, overlooks the universal properties of wetlands and the unifying concerns that motivate wetland scientists and practitioners on an international scale. In this special issue, diversity is reflected in the range of wetland types studied in various countries, yet the papers have critical themes in common. First, they acknowledge the fundamental importance of the hydrological regime in controlling wetland systems and services. Second, they adopt novel and practical approaches to issues of widespread and pressing concern, such as the role wetlands play in climate regulation and change, for local livelihoods, and to develop their restoration potential. Finally, all of the papers are concerned with a better understanding of wetland ecosystems so that the vital services they provide can continue to benefit society now and in the future.

\section{References}

Bardgett, R. D. \& D. A. Wardle, 2010. Aboveground-belowground linkages: biotic interactions, ecosystem process, and global change. Oxford University Press, Oxford.

Beccerra-Jurado, G., R. Harrington \& M. Kelly-Quinn, 2012. A review of the potential of surface flow constructed wetlands to enhance macroinvertebrate diversity in agricultural landscapes with particular reference to Integrated Constructed Wetlands (ICWs). Hydrobiologia. doi:10.1007/s10750-011-0866-2 (this issue).

Berg, M., C. B. Joyce \& N. G. Burnside, 2012. Differential responses of abandoned wet grassland plant communities to reinstated cutting management. Hydrobiologia. doi:10.1007/s10750-011-0826-x (this issue).

Dušek, J., H. Čížková, S. Stellner, R. Czerny \& J. Květ, 2012. Fluctuating water table affects gross ecosystem production and gross radiation use efficiency in a sedge-grass marsh. Hydrobiologia. doi:10.1007/s10750-012-0998-z (this issue).

Hannigan, E. \& M. Kelly-Quinn, 2012. Composition and structure of macroinvertebrate communities in contrasting open-water habitats in Irish peatlands: implications for biodiversity conservation. Hydrobiologia. doi:10.1007/ s10750-012-1090-4 (this issue).

Harrington, C., M. Scholz, N. Culleton \& P. G. Lawlor, 2012. The use of Integrated Constructed Wetlands (ICW) for the treatment of separated swine wastewaters. Hydrobiologia. doi:10.1007/s10750-011-0945-4 (this issue).

Kaštovská, E., T. Picek, J. Bárta, J. Mach, T. Cajthaml \& K. Edwards, 2012. Nutrient addition retards decomposition and $\mathrm{C}$ immobilization in two wet grasslands. Hydrobiologia. doi:10.1007/s10750-012-1017-0 (this issue).

Kimberley, S., O. Naughton, P. Johnston, L. Gill \& S. Waldren, 2012. The influence of flood duration on the surface soil properties and grazing management of karst wetlands (turloughs) in Ireland. Hydrobiologia. doi:10.1007/ s10750-012-1000-9 (this issue).

Kŏiv, M., I. Ostonen, C. Vohla, R. Mŏtlep, M. Liira, K. Lŏhmus, K. Kirsimäe \& U. Mander, 2012. Reuse potential of phosphorus-rich filter materials from subsurface flow wastewater treatment filters for forest soil amendment. Hydrobiologia. doi:10.1007/s10750-011-0944-5 (this issue).

Menezes, S., D. J. Baird \& A. M. V. M. Soares, 2010. Beyond taxonomy: a review of macroinvertebrate trait-based community descriptors as tools for freshwater biomonitoring. Journal of Applied Ecology 47: 711-719.

Millennium Ecosystem Assessment, 2005. Ecosystems and Human Health: Water and Wetlands Synthesis. World Resources Institute, Washington.

Mitsch, W. J. \& J. G. Gosselink, 2007. Wetlands. Wiley, Chichester.

Morrison, E. H. J., C. Upton, K. Odhiambo-K'oyooh \& D. M. Harper, 2012. Managing the natural capital pf papyrus within riparian zones of Lake Victoria, Kenya. Hydrobiologia. doi:10.1007/s10750-011-0839-5 (this issue).

Rosenthal, G., 2010. Secondary succession in a fallow central European wet grassland. Flora 205: 153-160.

Salm, J-O., M. Maddison, S. Tammik, K. Soosaar, J. Truu \& Ü. Mander, 2012. Emissions of $\mathrm{CO}_{2}, \mathrm{CH}_{4}$ and $\mathrm{N}_{2} \mathrm{O}$ from undisturbed, drained and mined peatlands in Estonia. Hydrobiologia. doi:10.1007/s10750-011-0934-7 (this issue).

Scholz, M., R. Harrington, P. Carroll \& A. Mustafa, 2007. The integrated constructed wetlands (ICW) concept. Wetlands 27: 337-354.

Schrautzer, J., A. Fichtner, A. Huckauf, L. Rasran \& K. Jensen, 2011. Long-term population dynamics of Dactylorhiza incarnata (L.) Soó after abandonment and re-introduction of mowing. Flora 206: 622-630.

Steffenhagen, P., D. Zak, K. Schulz, T. Timmermann \& S. Zerbe, 2012. Biomass and nutrient stock of submersed and floating macrophytes in shallow lakes formed by rewetting of degraded fens. Hydrobiologia. doi:10.1007/s10750-0110833-y (this issue).

Turner, R. K., S. Georgiou \& B. Fisher, 2007. Valuing ecosystem services: the case of multi-functional wetlands. Earthscan, London.

Vymazal, J. \& J. Šveha, 2012. Removal of alkali metals and their sequestration in plants in constructed wetlands treating municipal sewage. Hydrobiologia. doi:10.1007/ s10750-012-1018-z (this issue). 